\title{
The influence of near-field fluxes on seasonal carbon dioxide enhancements: results from the Indianapolis Flux Experiment (INFLUX)
}

\author{
Natasha L. Miles ${ }^{1 *}$ (D, Kenneth J. Davis ${ }^{1,2}$, Scott J. Richardson ${ }^{1}$, Thomas Lauvaux ${ }^{1,3}$, Douglas K. Martins ${ }^{1,4}$, \\ A. J. Deng ${ }^{1,5}$, Nikolay Balashov ${ }^{1,6}$, Kevin R. Gurney ${ }^{7}$, Jianming Liang ${ }^{7,8}$, Geoff Roest ${ }^{7}$, Jonathan A. Wang9,10 \\ and Jocelyn C. Turnbull11,12
}

\begin{abstract}
Background: Networks of tower-based $\mathrm{CO}_{2}$ mole fraction sensors have been deployed by various groups in and around cities across the world to quantify anthropogenic $\mathrm{CO}_{2}$ emissions from metropolitan areas. A critical aspect in these approaches is the separation of atmospheric signatures from distant sources and sinks (i.e., the background) from local emissions and biogenic fluxes. We examined $\mathrm{CO}_{2}$ enhancements compared to forested and agricultural background towers in Indianapolis, Indiana, USA, as a function of season and compared them to modeled results, as a part of the Indianapolis Flux (INFLUX) project.

Results: At the INFLUX urban tower sites, daytime growing season enhancement on a monthly timescale was up to 4.3-6.5 ppm, 2.6 times as large as those in the dormant season, on average. The enhancement differed significantly depending on choice of background and time of year, being 2.8 ppm higher in June and 1.8 ppm lower in August using a forested background tower compared to an agricultural background tower. A prediction based on land cover and observed $\mathrm{CO}_{2}$ fluxes showed that differences in phenology and drawdown intensities drove measured differences in enhancements. Forward modelled $\mathrm{CO}_{2}$ enhancements using fossil fuel and biogenic fluxes indicated growing season model-data mismatch of $1.1 \pm 1.7 \mathrm{ppm}$ for the agricultural background and $2.1 \pm 0.5 \mathrm{ppm}$ for the forested background, corresponding to $25-29 \%$ of the modelled $\mathrm{CO}_{2}$ enhancements. The model-data total $\mathrm{CO}_{2}$ mismatch during the dormant season was low, $-0.1 \pm 0.5 \mathrm{ppm}$.

Conclusions: Because growing season biogenic fluxes at the background towers are large, the urban enhancements must be disentangled from the biogenic signal, and growing season increases in $\mathrm{CO}_{2}$ enhancement could be misinterpreted as increased anthropogenic fluxes if the background ecosystem $\mathrm{CO}_{2}$ drawdown is not considered. The magnitude and timing of enhancements depend on the land cover type and net fluxes surrounding each background tower, so a simple box model is not appropriate for interpretation of these data. Quantification of the seasonality and magnitude of the biological fluxes in the study region using high-resolution and detailed biogenic models is necessary for the interpretation of tower-based urban $\mathrm{CO}_{2}$ networks for cities with significant vegetation.
\end{abstract}

Keywords: Carbon dioxide, Urban, Greenhouse gas, Fluxes, Background, INFLUX, Anthropogenic, Biogenic

*Correspondence: nmiles@psu.edu

${ }^{1}$ Department of Meteorology and Atmospheric Science, The Pennsylvania State University, University Park, PA 16802, USA

Full list of author information is available at the end of the article

\section{Background}

The ability to accurately and annually quantify urban greenhouse gas (GHG) emissions is essential for assessing the interim effectiveness of decadal-scale urban climate action plans (e.g., [1]). Each of numerous approaches to 
estimating urban $\mathrm{CO}_{2}$ emissions has strengths and weaknesses, and the approaches are ideally used synergistically to improve each other [2]. An advantage of in situ towerand building top- based atmospheric approaches is the ability to provide continuous quantification of emissions to support urban policy mitigation plans. Consequently, an increasing number of such GHG monitoring networks have been deployed in cities around the globe (e.g., [3-8].

The choice of background is critical for interpretation of data from urban $\mathrm{CO}_{2}$ mole fraction networks because of the need to isolate the urban signal from variations associated with weather $[9,10]$ and sources and sinks from other locations. The effect of background choices is an active area of research. Lauvaux et al. [11] used two-step optimization of the boundary conditions, first utilizing aircraft and CarbonTracker inverse system [12] mole fractions, and then optimizing within the inversion. McKain et al. [4] used $\mathrm{CO}_{2}$ mole fractions from a mountaintop site to represent the background $\mathrm{CO}_{2}$, as did Lauvaux et al. [13]. Verhulst et al. [8] analyzed four potential background sites for Los Angeles, California, and determined the annual average uncertainty in background using a local marine site to be roughly $10 \%$ of the median mid-afternoon $\mathrm{CO}_{2}$ enhancement for their 50-m AGL rooftop measurement site near downtown. For the $\mathrm{CO}_{2}$-MEGAPARIS experiment, also described by Bréon et al. [14] and Xueref-Remy et al. [15], Staufer et al. [7] used three $\mathrm{CO}_{2}$ measurement sites in a Lagrangian configuration, with the background used depending on strictly defined wind speed and wind direction parameters. The site used as background for northeasterly winds was located in a small village considered a rural area, and the background site for southwesterly winds was near the southwest corner of Paris, France, in a mixed urban and rural area. Sargent et al. [16] calculated a curtain of background values using data from two background sites $90-170 \mathrm{~km}$ from Boston, Massachusetts, combined with modelled vertical mole fraction gradients, and limited the analysis to days with wind directions within $\pm 40^{\circ}$ of the background to urban site vector. $\mathrm{CO}_{2}$ for each edge of the model domain boundaries was determined by Nickless et al. [6] using a Global Atmosphere Watch (GAW) station located $60 \mathrm{~km}$ to the south of Cape Town, South Africa. The determination of background for Cape Town was aided by its location on a peninsula. Mueller et al. [17] used modeling and geostatistical methods with synthetic data to determine optimal locations for four background towers in the Washington D.C./Baltimore area. Cities predominately downwind of large bodies of water or located in non-vegetated regions are simpler in terms of determination of background, but most cities, including those described above, are near other cities and/or surrounded by active vegetation, complicating the extraction of local signals.

The Indianapolis Flux Project (INFLUX) is a testbed for measuring urban GHG emissions in Indianapolis, Indiana $[2,18]$. For the dormant season in Indianapolis, roughly November-March, the biogenic effect on $\mathrm{CO}_{2}$ fluxes is relatively small compared to the fossil fuel contribution. Turnbull et al. [19] found that wintertime $\mathrm{CO}_{2}$ enhancement in Indianapolis was nearly equivalent to the fossil-fuel $\mathrm{CO}_{2}$ enhancement using a local background. Also in Indianapolis, Miles et al. [5] used a single predominantly upwind tower site $20 \mathrm{~km}$ to the southwest of the city edge as background for an analysis of inter-tower differences during the dormant season 2012-2013. Lauvaux et al. [20] found that inverse emission results differed by only $4 \%$ between using a single background and using a wind direction dependent background, for their primarily dormant season analysis of data between September 2012 and April 2013. Turnbull et al. [21] used flask measurements of ${ }^{14} \mathrm{CO}_{2}$ (comparing downwind towers to a local background site (Tower 01)) to determine that biogenic $\mathrm{CO}_{2}$ fluxes in Indianapolis are just $10 \%$ of the magnitude of fossil fuel $\mathrm{CO}_{2}$ fluxes in November and December.

For analyses encompassing the growing season (roughly April-October in the Northern Hemisphere mid-latitudes), and for cities without dormant seasons, however, biogenic contributions to the total flux are potentially substantial and must be addressed [6]. In the growing season, biological fluxes significantly impact the determination of the urban carbon budget $[19,22$, 23]. In addition to a strong seasonal cycle in biological $\mathrm{CO}_{2}$ fluxes, different vegetation types are known to exhibit different timing of fluxes. For example, crops have shorter growing seasons and more intense carbon drawdown than natural vegetation [24, 25]. Corbin et al. [26] found that simulating corn and soybean explicitly alters both the timing and magnitude of the net carbon fluxes compared to generic agriculture/grassland. Increasing agricultural land use and yields between 1961 and 2010 manifested in a $15 \%$ long-term increase in $\mathrm{CO}_{2}$ seasonal amplitude and a shift in overall vegetation growth by 1 to 2 weeks [27]. Differences in green-up dates of local vegetation were correlated with associated patterns in $\mathrm{CO}_{2}$ in Boston [28]. In the U.S. Upper Midwest, Miles et al. [9] found large growing season mean differences in $\mathrm{CO}_{2}(5.1 \mathrm{ppm})$ between a tower site dominated by corn versus one dominated by grass. Comparatively, a downtown tower (Tower 03) in Indianapolis measured $2.9 \mathrm{ppm}$ higher than a forested tower (Tower 01) during the dormant season. Thus biological fluxes can be on the same order of magnitude as anthropogenic fluxes and need 
to be taken into account when interpreting urban $\mathrm{CO}_{2}$ observations.

Evaluation of the impact of background biological fluxes on urban $\mathrm{CO}_{2}$ flux estimates has, to date, relied heavily upon simulations of these fluxes. Nickless et al. [6] used the Community Atmosphere Biosphere Land Exchange (CABLE) model to represent biogenic fluxes for their inversion of $\mathrm{CO}_{2}$ fluxes in Cape Town, South Africa. While the inversion was able to improve the total flux estimates, it was not able to disaggregate the biogenic from anthropogenic fluxes because of the large uncertainties in the biogenic flux priors. Sargent et al. [16] used the UrbanVPRM and a biomass map to simulate the impact of rural biology on background $\mathrm{CO}_{2}$ for the city of Boston. Heimburger et al. [29] and other aircraft studies show that background $\mathrm{CO}_{2}$ mole fractions often exhibit complex spatial structure. Balashov et al. [30] show that Indianapolis background for $\mathrm{CH}_{4}$, another greenhouse gas produced by various anthropogenic and natural sources, varies in space with large random and systematic differences across background sites, likely attributable to large plumes from coal mines in southwest Indiana. Direct evaluation of background $\mathrm{CO}_{2}$ via longterm observation is needed to assess the accuracy of our urban inversion systems.

The goal of this paper is to document the effects of background choice on $\mathrm{CO}_{2}$ enhancements above background measured with an urban tower-based network. We first consider the differences between background towers as a function of wind direction and season. Two potential background towers were available for January 2013-December 2018, and an additional one was available for April 2017-December 2018. We calculated 31-day median afternoon enhancements above each of the primary background towers, and composited over 5.7 years of data to determine yearly cycles of enhancements at each tower. We compared the results from each of the background towers, and made a simple prediction to explain the difference between the towers based on their land cover types. We then compare these results to forward model $\mathrm{CO}_{2}$ enhancement using fossil fuel and biogenic fluxes.

\section{Methods}

\section{Study site}

The locations of the INFLUX ground-based $\mathrm{CO}_{2}$ measurement sites and the city of Indianapolis, Indiana, in the U.S. Midwest, are shown in Fig. 1. Indianapolis, in Marion County, Indiana, was the $17^{\text {th }}$ most populous city in the U.S. in 2019, with an estimated population of about 876,000 [31]. The predominant wind direction in Indianapolis is from the southwest, with southerly

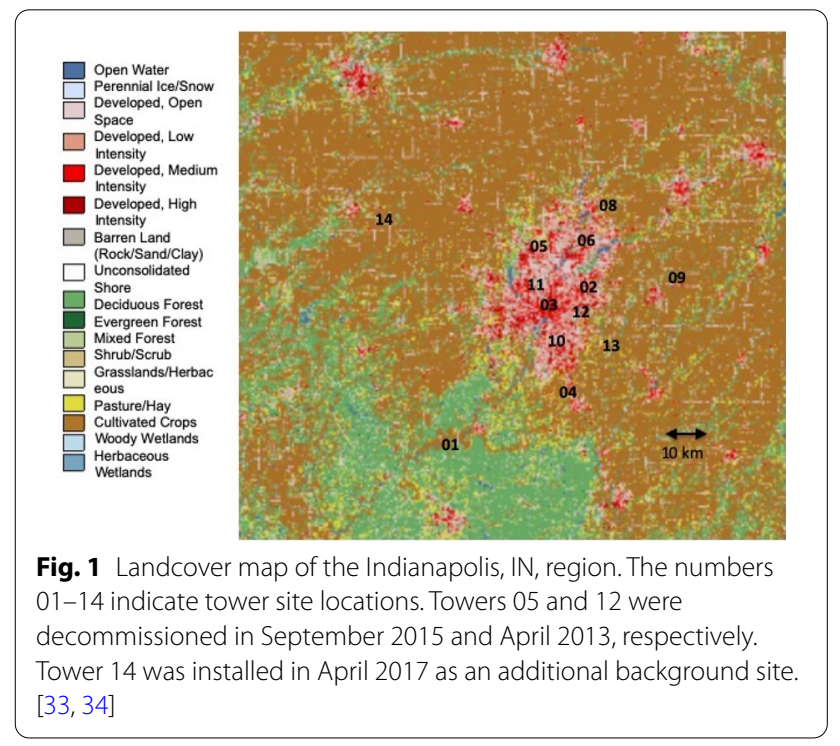

through westerly winds occurring $37.7 \%$ of the times with appreciable wind speed throughout 2018 [32]. Three of the INFLUX tower sites are considered potential background sites: Towers 01,09 , and 14. Tower 01 is upwind of the edge of the city (as defined by the beltway encircling the city) by $20 \mathrm{~km}$ when the wind is from the predominant southwesterly direction, and is on the northern edge of a forested area (Fig. 1). Tower 09 is located in an agricultural area $24 \mathrm{~km}$ east of the edge of Indianapolis. Tower 14 was installed in late April 2017, and is northwest of the city by $50 \mathrm{~km}$, again in a primarily agricultural region. The remaining tower sites are in and around Indianapolis [5].

The primary biogenic land cover types in the region surrounding Indianapolis (Fig. 1) are forest, agricultural (including corn and soy), and grassland/pasture, and the biological fluxes from these land cover types differ significantly in their seasonal cycles (Fig. 2). The forest fluxes shown in Fig. 2 were measured at a flux tower [35] in the Morgan Monroe State Forest (MMSF), $29 \mathrm{~km}$ to the south of Tower 01 . The monthly average flux is negative in the growing season (i.e., $\mathrm{CO}_{2}$ drawdown) beginning in May and extending through September. The forest flux was weakly positive throughout the remainder of the year. A corn/soy flux tower [36] was located in Bondville, Illinois, $176 \mathrm{~km}$ WNW of Tower 01. Corn and soy were grown in the field surrounding the flux tower in alternating years. The growing season, as indicated by negative fluxes, for corn begins later than for the forest, in June and extended through August. The soy flux was negative only for the months of July and August. As for the forest, the 


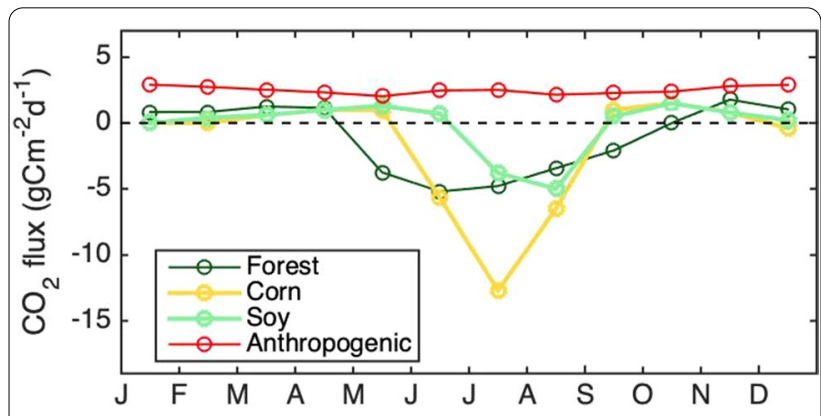

Fig. 2 a Mean annual cycle of biological $\mathrm{CO}_{2}$ fluxes (net ecosystem exchange; NEE) for a forest site (dark green), a corn site (yellow) and a soybean site (light green). The forest fluxes are the 5-year mean measured at the Morgan Monroe State Forest [35] and the corn and soybean fluxes are the 3-year mean measured in Bondville, Illinois

[36]. b Domain-averaged 31-day median (fossil fuel (Hestia) emissions as a function of time of year for 2014

agricultural fluxes were weakly positive during the dormant season. Grassland/pasture tends to be on the edges of other landcover types in small patches $([5,37]$ Fig. 1).

The domain-averaged fossil fuel $\mathrm{CO}_{2}$ flux (Hestia, Fig. 2) exhibited higher values in the colder months of November-March, due to energy production for heating (e.g., [7, 13, 38]). The summer increase in fossil fuel emissions was likely attributable to energy production for cooling $[39,40]$.

\section{Instrumentation}

The INFLUX in situ observation network includes tower sites measuring greenhouse gases using wavelengthscanned cavity ring down spectroscopic (CRDS) instruments (Picarro, Inc., models G1301, G2301, G2302, and G2401). The full network consists of twelve sites but with site re-locations throughout the period, there are a total of fourteen measurement locations. We focus on $\mathrm{CO}_{2}$ measured during the period January 2013-December 2018 for this paper. The instruments were deployed at the base of existing communications towers, with $1 / 4$ " $(0.64 \mathrm{~cm})$ sampling tubes installed as high as possible on each tower (39-136 above ground level (AGL)). Four of the towers had multiple measurement heights (Table 1).

A linear calibration based on three to five NOAA tertiary reference tanks was applied to the instruments prior to deployment and following any manufacturer repairs, and an intercept-only calibration was applied in the field every $23 \mathrm{~h}$ based on one or two calibrated reference tanks. For the majority of the time period, the air samples were dried using Nafion dryers (MD-070-96S-2, PermaPure) in reflux mode, with an internal water vapor correction applied for the effects of the remaining water vapor $(<0.2$ or $0.6 \%$, depending on the length of the Nafion dryer). We used hourly means of $\mathrm{CO}_{2}$, which were reported on the WMO X2007 scale and are publicly available [5, 37]. Compatibility of the INFLUX network, both within network and compared to the global network, was assessed via co-located NOAA flask systems [41] at Towers 01, 02, 03, 06, 09, and 10, and round-robin

Table 1 Measurement height(s) as of 2013 (with 2018 shown in parentheses if different) and predominant landcover type(s) at INFLUX towers

\begin{tabular}{|c|c|c|c|c|}
\hline & Predominant landcover type(s) & Latitude $\left({ }^{\circ} \mathrm{N}\right)$ & Longitude ( $\left.{ }^{\circ} \mathrm{W}\right)$ & $\begin{array}{l}\text { Measurement } \\
\text { height(s) (m AGL) }\end{array}$ \\
\hline Tower 01 & Forest/agriculture & 39.5805 & 86.4207 & $10 / 40 / 121$ \\
\hline Tower 02 & Urban & 39.7978 & 86.0183 & $10 / 40 / 136(136)$ \\
\hline Tower 03 & Urban & 39.7833 & 86.1652 & $10 / 20 / 40 / 54$ \\
\hline Tower 04 & Urban/agriculture & 39.5925 & 86.1009 & 60 \\
\hline Tower 05 & Urban & 39.8947 & 86.2011 & 125 \\
\hline Tower 06 & Urban & 39.9201 & 86.0280 & 39 \\
\hline Tower 07 & Urban & 39.7739 & 86.2724 & 58 \\
\hline Tower 08 & Agriculture/urban & 40.0411 & 85.9734 & 41 \\
\hline Tower 09 & Agriculture & 39.8627 & 85.7448 & 10/40/70/130(130) \\
\hline Tower 10 & Urban & 39.7181 & 86.1436 & 40 \\
\hline Tower 11 & Urban & 39.8403 & 86.1763 & 130 \\
\hline Tower 12 & Urban & 39.7637 & 86.0403 & 40 \\
\hline Tower 13 & Agriculture & 39.7173 & 85.9417 & 87 \\
\hline Tower 14 & Agriculture & 39.9971 & 86.7396 & 76 \\
\hline
\end{tabular}

Additional tower details are listed in Miles et al. [5, 37]

Towers considered as background options are italicized 
type testing using multiple NOAA-calibrated tanks, indicating compatibility of $0.18 \mathrm{ppm} \mathrm{CO}_{2}$. Further details of the instrumentation and compatibility are described by Richardson et al. [42] and Miles et al. [5].

Because of unexpectedly low $\mathrm{CO}_{2}$ mole fractions measured at Tower 14 during the growing season of 2017, a separate instrument with a separate $1 / 1 "(0.64 \mathrm{~cm})$ tube installed to the top of the tower was co-located at the site for a period of several weeks to eliminate the possibility of further leaks or other instrument problems. The additional instrument was calibrated prior to deployment and installed with no drying, relying on the internal water vapor correction for $\mathrm{CO}_{2}$. From 20 to 26 August 2018, both instruments sampled from the top of the tower and the difference between the two (primary instrument secondary instrument) was very small, $-0.11 \pm 0.12 \mathrm{ppm}$.

\section{Wind measurements}

The wind data used to characterize overall synoptic patterns in the city were measured at the Indianapolis International Airport, outside the southwest corner of the city. The data are part of the Integrated Surface Dataset (https://www.ncdc.noaa.gov/isd). The weather station at the airport uses the Automated Surface Observing System (http://www.nws.noaa.gov/asos/pdfs/aum-toc.pdf). The accuracy of wind speed is $\pm 1.0 \mathrm{~ms}^{-1}$ or $5 \%$ (whichever is greater) and the accuracy of wind direction is $5^{\circ}$ when the wind speed is $\geq 2.6 \mathrm{~ms}^{-1}$. Wind directions are not reported for periods in which the wind speed is less than $1.6 \mathrm{~ms}^{-1}$. The height of the wind instrument is about $10 \mathrm{~m}$ AGL. The wind data are reported at a single point in time recorded within the last $10 \mathrm{~min}$ of each hour.

For the purpose of categorizing afternoon-average $\mathrm{CO}_{2}$ in terms of wind direction, we calculated vector averages of afternoon winds.

\section{Determination of land cover surrounding tower locations}

In order to characterize each of the INFLUX tower locations in terms of the surrounding land cover types, we considered the land cover within $10 \mathrm{~km}$ of each tower. This radius covers approximately $80 \%$ of the influence for the towers, determined via afternoon influence functions simulated for January-April 2013 at 1-km resolution with the Lagrangian Particle Dispersion Model (LDPM) [20, 43], using inputs from the Weather Research Forecasting-Four-Dimensional Data Assimilation modeling system (WRF-FDDA-CO ${ }_{2}$ ) [44-46].

Land cover data was obtained from the United States Department of Agriculture National Agriculture Statistics Service (NASS; $[47,48]$ ). The categories with significant percentages in the Indianapolis area included corn, soy, open water, developed/open space, developed/low intensity, developed/medium intensity, developed/high intensity, deciduous forest, and grass/pasture. The most recent year available from NASS, 2018, was used for the analysis. Corn and soy are typically rotated each year, but since we are considering a large area, a single year is a reasonable representation of the overall landcover for the time period.

We defined the total urban fraction for each tower as the fraction of area categorized as "developed", compared to the total area within a $10-\mathrm{km}$ radius $(80 \%$ of the footprint) of each the towers. We then ranked the towers in terms of total urban fraction. Each category of "developed" (i.e., open, low-, medium- and high-intensity) was weighted equally for this purpose, given that the proportions of these categories do not differ considerably between the INFLUX sites.

The prevalence of different land cover types differed considerably between the INFLUX towers. The percentages of land cover types within each category surrounding each tower are shown in Fig. 3. The towers with the highest urban fractions within the surrounding area were Tower 03 (94.5\%), Tower 11 (91.4\%), Tower 10 (89.4\%), Tower 07 (80.7\%), Tower 05 (80.6\%), Tower $12(77.2 \%)$, Tower $02(74.0 \%)$, and Tower 06 (70.6\%). We consider these "urban" towers. The remaining towers were surrounded by $48 \%$ or less urban fraction and are considered "rural" towers. The potential background towers, Towers 09,01 and 14 were surrounded by $12.3 \%, 12.3 \%$ and $6.2 \%$ urban land cover, respectively. Tower 01 was surrounded by the highest fraction of deciduous forest (35.1\%). Towers 14 and 09 were primarily agricultural sites (covering 78.5 and $70.7 \%$, respectively, of the surrounding areas). Tower 14 had the highest percentage of corn (36.4\%), with Tower 09 at $30.4 \%$. Soy is the other major crop in the region. Note that the radius considered $(5,10,18 \mathrm{~km})$ for the landcover determination does somewhat affect the ordering of the sites from most urban to least urban, but for all cases, there is a clear grouping between the urban sites (Sites 02, 03, 05, 06, 07, 10, 11, and 12) and the rural sites $(01,04,08,09,13$, and 14$)$.

\section{Observational analyses}

In this paper, we focused on afternoon average $\mathrm{CO}_{2}$, with the mean calculated over the period $1700-2200$ UTC (1200-1700 LST). The atmospheric boundary layer $(\mathrm{ABL})$ is typically well mixed during these hours, which allows simpler interpretation of the measurements (e.g., [49]).

We considered three towers as potential background sites in this paper. Miles et al. [5] used Tower 01 (forested) as the background tower for the INFLUX network during the dormant season, and determined the enhancement in $\mathrm{CO}_{2}$ of the other towers compared to it. 


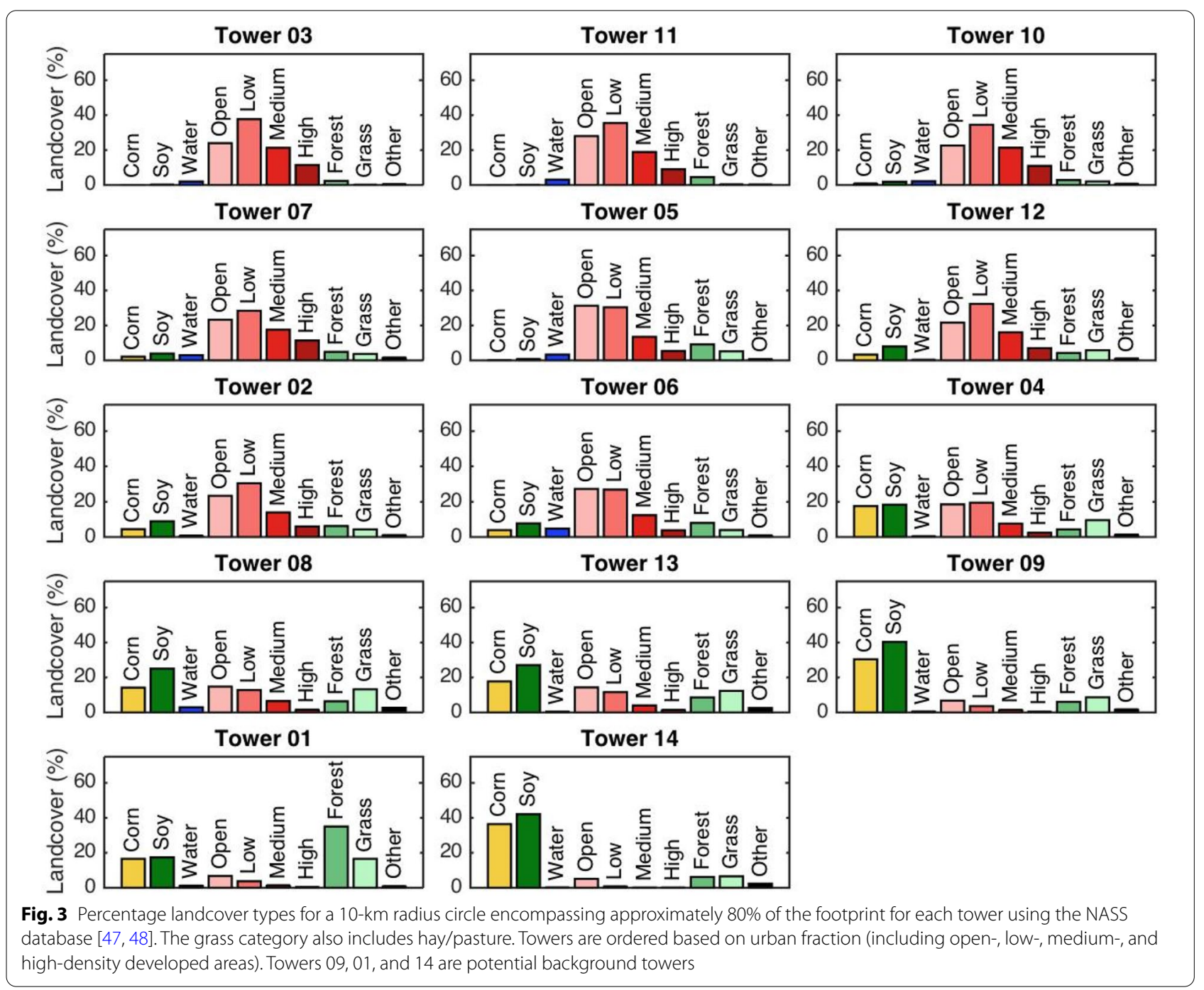

Here we considered Towers 09 and 14 (both agricultural) as additional background towers. Both Towers 01 and 09 data were available for the majority of the analysis period, January 2013-December 2018, but Tower 14 was only available from April 2017 through December 2018.

We compared the $\mathrm{CO}_{2}$ measured at the INFLUX sites by calculating the 31-day running median of the enhancement in $\mathrm{CO}_{2}$ for each of the towers from Tower 01 and from Tower 09. Here we use the term enhancement although the difference can be negative, and we note that we have not isolated the anthropogenic enhancement with this calculation. The 31-day running median was chosen to focus on seasonal variability. We excluded data points for which any of the background towers were downwind of the urban area (afternoon average wind directions of $20-65^{\circ}$ (Tower 01 in urban plume) and $235-280^{\circ}$ (Tower 09 in urban plume). To determine these wind directions, we considered the angle between the background towers and the geometric edges of the urban area, as defined as the region within the expressway encircling Indianapolis (I-465) and the differences between background towers as a function of wind direction in the dormant season. The urban plume was not apparent at Tower 14. Furthermore, median results centered within 10 days of extended data gaps attributable to instrument malfunctions were excluded. We averaged these results for each day of the year for the available years between January 2013 and December 2018 to form annual cycles of smoothed composited $\mathrm{CO}_{2}$ differences. The standard deviation of the data from each of the available years was used as an estimate of the variability. We compared the results using Tower 09 as a background to those using Tower 01 as a background. The enhancements at each tower using these two different 
backgrounds can be compared since the same wind directions were excluded from each. We have primarily approached the background in an Eulerian sense, comparing each tower's measurements to a background at the same point in time, afternoon averages for this case. We also considered a more Lagrangian approach, utilizing a wind-direction dependent background, with Tower 01 as a background for wind directions from the west (180$360^{\circ}$ ) and Tower 09 as a background for wind directions from the east $\left(0-180^{\circ}\right)$, as done by Lauvaux et al. [20].

Assuming no missing data, the difference in each tower (Tower $\mathrm{N}$ ) enhancement using Tower 01 as a background $\left(\mathrm{CO}_{2}\right.$, Tower N $\left.-\mathrm{CO}_{2, \text { Tower } 01}\right)$ and those using Tower 09 as a background $\mathrm{CO}_{2}$, Tower $\mathrm{N}-\mathrm{CO}_{2 \text {,Tower } 09}$ is equivalent to subtracting Tower 09 from Tower 01 , since $\mathrm{CO}_{2, \text { Tower } N}$ cancels out. To compare the differences caused by background choice to the enhancement, we normalized the difference in enhancement between using two different background towers by the enhancement using Tower 01 as background and determined the percent difference.

We hypothesize that the differences between Tower 09 and Tower 01 (and thus between the enhancements using these two towers as background) to be attributable to differences in the primary land cover types and corresponding fluxes surrounding these towers. For a measurement site with a finite number of landcover types $(l c)$ in the surrounding region, the $\mathrm{CO}_{2}$ measured is related to the mean flux from each landcover type $\left(F_{l c}\right)$ and the fractional area of that landcover type $\left(f_{l c}\right)$,

$$
\mathrm{CO}_{2}=a \sum_{l c=1}^{N} F_{l c} f_{l c,}
$$

where $a$ is a constant. The landcover surrounding Towers 09 and 01 is predominately agricultural and forest, with Tower 09 having a higher percentage of agricultural landcover $(71 \%)$ and Tower 01 having a higher percentage of forest landcover (35\%) and a smaller portion of agricultural landcover (34\%). Following from Eq. (1), we assert that,

$$
\Delta C O_{2} / a=\left(F_{\text {forest }} f_{\text {forest }, 01}+F_{\text {agr }} f_{\text {agr }, 01}\right)-\left(F_{\text {forest }} f_{\text {forest }, 09}+F_{\text {ag }} f_{\text {agr }, 09}\right)
$$

where $\mathrm{ACO}_{2}$ is the difference in $\mathrm{CO}_{2}$ mole fraction between the two tower sites, $F_{\text {forest }}$ and $F_{a g r}$ are the forest and the mean of the corn and soy agricultural fluxes, and $f_{\text {forest }}$ and $f_{\text {agr }}$ are the forest and agricultural land cover fractions for the area of $10 \mathrm{~km}$ radius surrounding each site. Towers 09 and 01 have small and equal amounts of urban landcover (12.3\% in the surrounding $10-\mathrm{km}$ radius) so the urban terms cancel. We note that corn and soy are typically rotated from year to year and have similar areal coverage within the region. For these reasons, although corn and soy have very different fluxes, we can simplify the calculation by averaging the corn and soy fluxes to determine an agricultural flux.

This equation assumes that all factors other than the surface fluxes (such as entrainment and advection) are equivalent at the two tower locations. The equation also assumes that the landcover types are not significantly dependent on distance or direction from the tower. This assumption is reasonable for the two towers in Eq. (2) as they are located in homogenous areas, but would not be so for Tower 02, for example, on the downwind edge of the city. We used the forest, corn and soy fluxes shown in Fig. 2a to represent the seasonal pattern of ecosystem flux and predicted midday $\mathrm{ABL} \mathrm{CO}_{2}$ mole fraction differences between these two background sites. We then compared the seasonal pattern of the predicted $\mathrm{CO}_{2}$ difference to the measured differences at Tower 01 and 09.

\section{Modelled tower $\mathrm{CO}_{2}$}

We calculated forward modelled $\mathrm{CO}_{2}$ dry mole fractions at each of the INFLUX towers by convolving tower footprints, representing the relationship between mole fractions and surface fluxes with fossil fuel emissions and biogenic fluxes. The tower footprints were simulated using transport field derived from the Weather Research and Forecasting model (WRFv3.6.1, [50] in Four-Dimensional Data Assimilation mode for the inner 1-km resolution $87 \mathrm{~km} \times 87 \mathrm{~km}$ domain [51]. Data from World Meteorological Organization surface stations within the model domain were assimilated to nudge the model to the observations. The transport fields were then coupled offline to the Lagrangian Particle Dispersion Model [11, $43,52]$ in backward mode.

Fossil fuel emissions from the Hestia $\mathrm{CO}_{2}$ emissions inventory product $[53,54]$, available for each of eight economic sectors (residential, on-road mobile, off-road mobile, industrial, commercial, electricity production, airport, and railroad) were used. Hestia emissions were aggregated from the initial building-level product to 1-km resolution, covering Marion County and the eight surrounding counties.

For biogenic fluxes, we used the urban Vegetation Photosynthesis and Respiration Model (VPRM, [55, 56], driven by greenness data from the Moderate Resolution Imaging Spectroradiometer (MODIS) satellite product and climate data from the North America Regional 
Reanalysis (NARR). The fraction of impervious surface area from the National Land Cover Database [47] within each pixel was used to adjust the carbon fluxes for the impact of urbanization on ecosystem function. Nonpaved portions of the city were defined as deciduous broadleaf forest. Distributions for four land cover types (corn, soy, grassland/pasture, and forest) were derived from the United States Department of Agriculture National Agriculture Statistics Service (NASS; [47, 48]), and the VPRM parameters were optimized for these land cover types [57] to produce hourly carbon fluxes at $1-\mathrm{km}$ resolution as the weighted average of carbon fluxes from each type. Note that Tower 14 is outside the domain of the VPRM results and is thus not included in the modeldata mismatch analysis.

We then compared the 31-day running median forward modelled $\mathrm{CO}_{2}$ enhancements for 2014 to observed $\mathrm{CO}_{2}$ enhancements for the same year. We used 1200-1700 LST, with the footprints incorporating fluxes in the $4 \mathrm{~h}$ preceding the observations. Wind directions for which either Tower 01 or Tower 09 were within the urban plume were excluded in both the model results and the observations. We then calculated urban site (Towers 02, 03, 06, 07, and 10) averaged model-data mismatch as a function of month of year. Although the percentage of urban landcover surrounding Tower 11 was quite high, we did not include it in the urban site calculations because the forward modelled anthropogenic $\mathrm{CO}_{2}$ at Tower 11 was very low.

\section{Results}

\section{$\mathrm{CO}_{2}$ enhancements above background Observed $\mathrm{CO}_{2}$ enhancements}

When comparing $\mathrm{CO}_{2}$ measured at INFLUX towers to a background tower throughout the year, biogenic effects were a dominant feature. The smoothed composited midday $\mathrm{ABL} \mathrm{CO}_{2}$ mole fraction enhancements relative to Tower 09 (agricultural) are shown in Fig. 4. The overall pattern, consistent for most of the towers, was a maximum in August, a secondary maximum in December-January, and minima in June and October. While anthropogenic fossil fuel $\mathrm{CO}_{2}$ emissions have a seasonal pattern (Fig. 2), the intensity of the growing season enhancements is attributable to biogenic effects primarily at the background tower, as will be described.

Not surprisingly, the towers with highest urban fraction in the surrounding area as shown in Fig. 3 exhibited generally higher smoothed composited $\mathrm{CO}_{2}$ enhancements relative to agricultural Tower 09 (Fig. 4). There was a clear demarcation between the 'urban' towers, those with greater than $70 \%$ surrounding urban land cover (Towers 03, 11, 02, 10, 07, and 06), and the 'rural' towers with $48 \%$ or less urban fraction (Towers $08,04,13,01$,

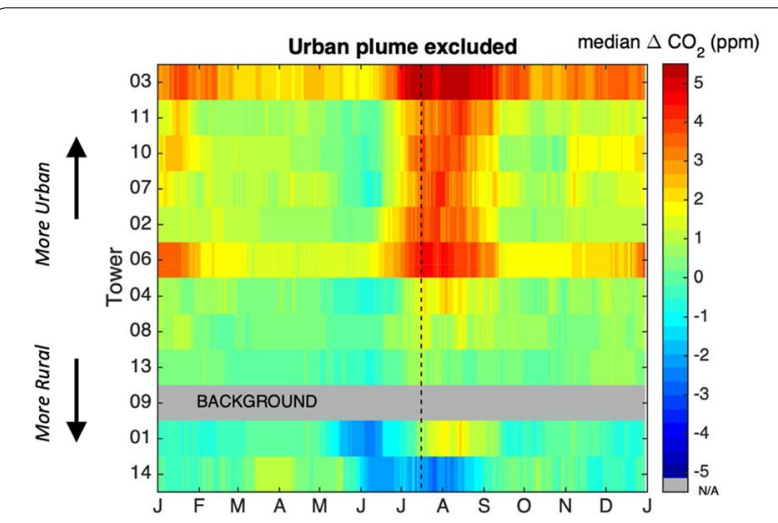

Fig. 4 Composited 31-day running median afternoon-average $\mathrm{CO}_{2}$ enhancements from Tower 09 for each of the towers, using data from January 2013 through December 2018. The towers are ordered by urban fraction (including high-, medium-, and low-density urban land cover, as discussed in " $\mathrm{CO}_{2}$ enhancements above background" section. Tickmarks indicate the beginning of each time period. Data for which Tower 01 or Tower 09 was influenced by the urban plume were excluded from the analysis (WSW and NE). Dashed line indicates July 15. Non-background towers deployed for less than 3 years are not shown (Towers 05 and 12). Tower 09 enhancement compared to Tower 09 is zero, by definition, but the row is included for consistency

and 14). The dominant feature of this figure, the maxima in July/August, was likely attributable to the reduced agricultural and forested land cover within the footprints of the urban towers and thus reduced biogenic uptake of $\mathrm{CO}_{2}$ compared to the background tower. In the dormant season, the higher urban tower enhancements were likely due to larger anthropogenic fluxes than for the rural sites. The August enhancements for the urban towers averaged $4.2 \mathrm{ppm}, 2.6$ times as large as the February urban tower enhancements, which averaged $1.6 \mathrm{ppm}$. The rural Towers $08,04,13$, and 01 also exhibited peak growing season maxima compared to Tower 09 but in the range of $1.0-2.5 \mathrm{ppm}$ rather than $4.3-6.5 \mathrm{ppm}$ for the urban towers. The notable difference between Tower 14 and Tower 09 (both agricultural) is discussed in "Agricultural tower $\mathrm{CO}_{2}$ background differences" section.

\section{Sensitivity of urban $\mathrm{CO}_{2}$ enhancement to the choice of background}

The INFLUX urban tower-average observed enhancements (Towers 02, 03, 06, 07, and 10) were sensitive to the choice of background tower (Fig. 5) during the growing season. While the overall pattern of enhancements (i.e., large summertime enhancement) was evident when comparing to either forested Tower 01 or agricultural Tower 09, the timing of the initiation of the growing season peak differed. The difference in enhancements using the different background towers was largest between May and September, and switched sign in July. In June 


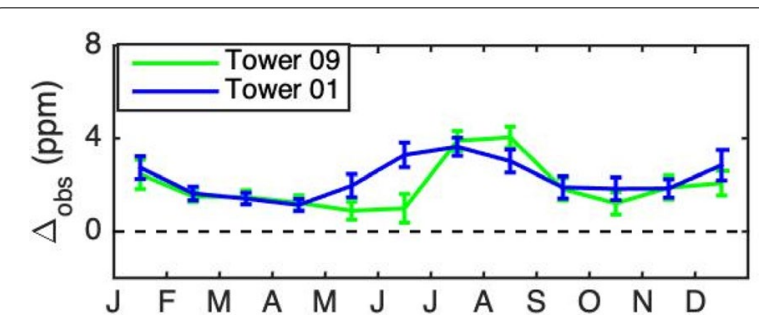

Fig. 5 Observed $\mathrm{CO}_{2}$ enhancement using Tower 09 (agricultural) as a background (green) and Tower 01 (forested) as a background (blue), composited over 2013-2018, and averaged over INFLUX urban towers. Wind directions for which either Tower 01 or Tower 09 are in the urban plume have been excluded. Only afternoon hours (1200-1700 LST) are included. Error bars indicate the standard error amongst the urban towers

the difference between using Tower 01 as a background and using Tower 09 as a background was $-2.8 \mathrm{ppm}$ and in August the difference was $1.8 \mathrm{ppm}$. For the dormant season, the difference in enhancement incurred by using different backgrounds was relatively small, $0.4 \mathrm{ppm}$ on average.

We postulate that the differences between the enhancements using these two background towers is attributable primarily to the rural biogenic signal. Shown in Fig. 6a is the observed difference between these two background towers, composited over 2013-2018 and for the year for which modelled results are available (2014). The growing season differences between the two towers were stronger in August-September 2014, outside of one standard deviation from the mean of the years, but not as pronounced for May-June. The predicted seasonal pattern $\mathrm{CO}_{2}$ difference between Tower 09 and Tower 01, based on forest and agricultural fluxes (Fig. 2a) are shown in Fig. 6b. The prediction, based on Eq. 2, is dimensionless and the focus is on relative trends of the differences (i.e., the shape of the curve). As in the composited observations for 2013-2018 (Fig. 6a), the predicted pattern was low from January through April. In May, Tower $01 \mathrm{CO}_{2}$ was predicted to be its greatest magnitude lower than Tower $09 \mathrm{CO}_{2}$. This is attributable to forest drawdown in the area surrounding Tower 01. Leaf-out usually occurs in the Morgan-Monroe Forest south of Tower 01 beginning at the end of April and is $80 \%$ complete by the month of May [35], compared to agricultural drawdown which begins later in the year, June for corn and July for soybean (Fig. 2a). This conclusion is consistent with large enhancements noted when the wind was from the south in Additional file 1: Fig. S3c. The predicted pattern in background tower differences (Fig. 6b) was similar to the observed minimum (Fig. 6a) in June, but slightly ahead in time. The Tower $09 \mathrm{CO}_{2}$ was predicted to be its greatest magnitude lower than Tower 01 in mid-July, only a

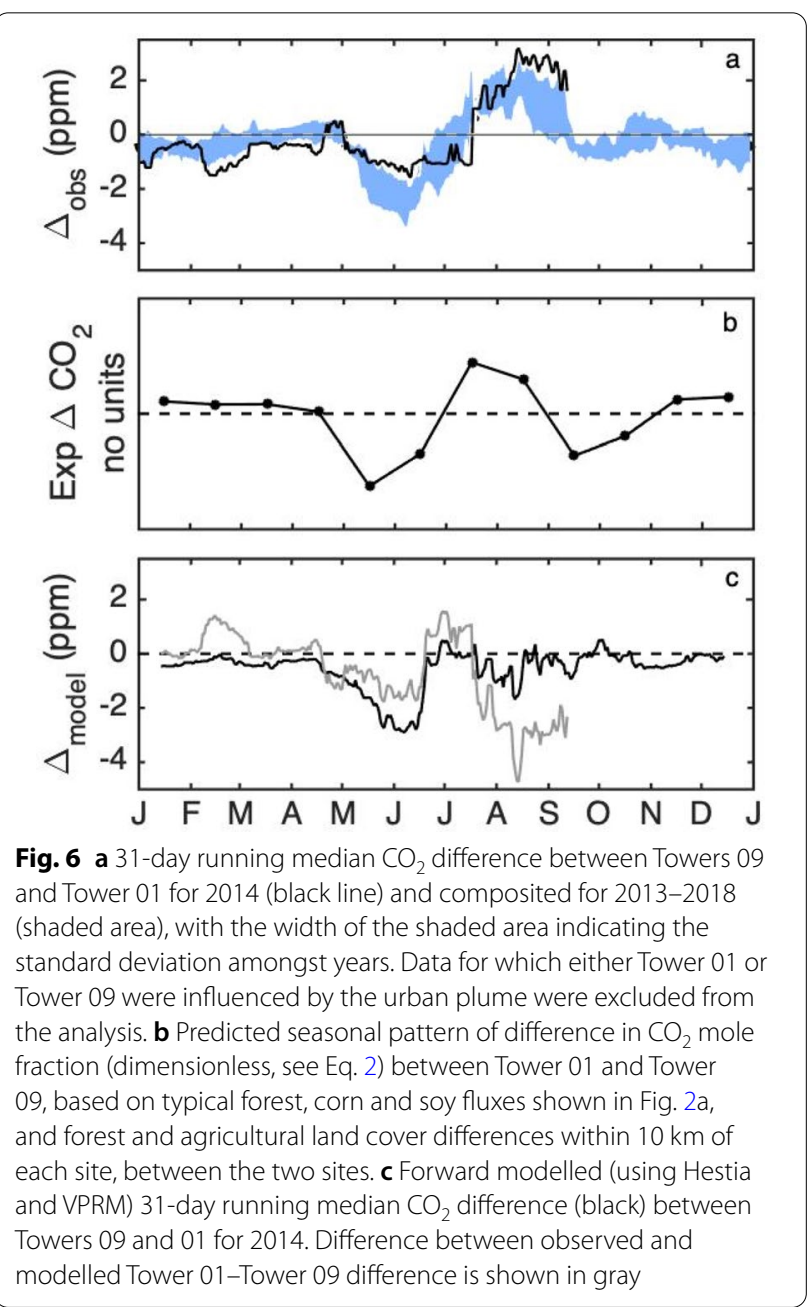

2-week shift from the observed pattern. That is, by midJuly, the agricultural fluxes in the footprint of Tower 09 were maximally larger than the forest fluxes in the footprint of Tower 01. While the predicted $\mathrm{CO}_{2}$ difference was small in November and December, as observed, the prediction indicated an additional minimum in September (about one half the magnitude of the minimum in May) that was not observed in the tower data. According to the fluxes in Fig. 2a, the forest was expected to continue to draw down $\mathrm{CO}_{2}$ in September, whereas the agricultural fluxes indicated small magnitude respiration. The tower results, however, indicated the both forest and agricultural fluxes were roughly balanced by mid-September, averaged over the time period of the dataset.

The forward model using VPRM and Hestia fluxes predicts an observed negative difference between Towers 09 and 01 in May and June and was largely consistent with observed differences throughout the rest of the year, but missed the positive difference in August and 
September (Fig. 6c). For May-mid June, the differences were $-1.0 \mathrm{ppm}$, Then, as for the prediction based on simple fluxes and landcover types, the mismatch switches sign and averages $+0.9 \mathrm{ppm}$ for mid June-mid July. In the later part of the summer, August through mid-September, the model predicts the towers to have nearly the same $\mathrm{CO}_{2}$, missing the $+3.0 \mathrm{ppm}$ observed difference. Improvements in the biogenic model can minimize these differences. Additionally an inversion using $\mathrm{CO}_{2}$ and $\mathrm{CO}$ mole fractions can optimize both the fossil and the biogenic $\mathrm{CO}_{2}$ separately [52].

\section{Differential footprints}

A box model assumes that the species of interest measured downwind is that measured at an upwind location, changed only by the fluxes from the surface below the box. This approach is not appropriate for interpretation of the application described here because the influence function for each tower decreases exponentially with distance from the towers [43] and thus the tower footprints do not overlap to a large degree. Here we have considered one background regardless of wind direction in an Eulerian framework (ignoring wind direction for which either background tower was within the urban plume), but biological fluxes must be considered for more Lagrangian approaches (following an air parcel from a background tower to an urban tower) as well. Using a wind-direction-dependent background while still excluding urban plumes for the background towers yielded similar results in terms of predominant growing season enhancement not likely to be attributable to changing anthropogenic emissions (Additional file 1: Fig. S4c). Contributions to the $\mathrm{CO}_{2}$ measured at a tower decrease exponentially with distance (e.g., [43]. The footprints for a background and an urban tower overlap, but each tower is influenced preferentially by nearby sources, and we call this the differential footprint. If we consider a contour containing a given percentage of the influence, we can visualize the differing effect of the rural biological flux as in Fig. 7.

\section{Modelled urban-tower averaged $\mathrm{CO}_{2}$ enhancements}

The forward model predicted a growing season increase in enhancement in $\mathrm{CO}_{2}$ at the tower sites (Fig. 8a). Furthermore, the model was able to capture the observed timing difference in green-up between using forested Tower 01 and agricultural Tower 09 as backgrounds, in general. However, modelled enhancements were larger than observed (Fig. 5) during the growing season. The modelled difference between the $\mathrm{CO}_{2}$ of the background towers was similar to that observed in June (2.9 $\mathrm{ppm}$ modelled, compared to the observed $2.5 \mathrm{ppm}$ ), but in August, the model predicted the forested background tower $\mathrm{CO}_{2}$ to be lower than the agricultural tower by

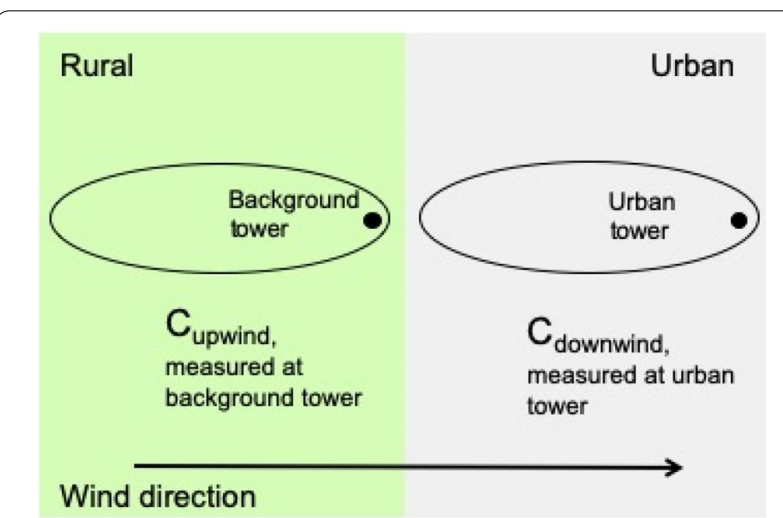

Fig. 7 Schematic illustrating the "differential footprint" concept, as opposed to a simple box model. The green area indicates rural landcover surrounding the background tower and the gray area indicates urban landcover. The ellipses indicate the areas contributing the majority of the signal for each tower, since the influence decreases exponentially with distance from the tower. $80 \%$ of the influence for the INFLUX towers is within $10 \mathrm{~km}$, on average, and for example, Towers 01 and 02 are separated by $43 \mathrm{~km}$

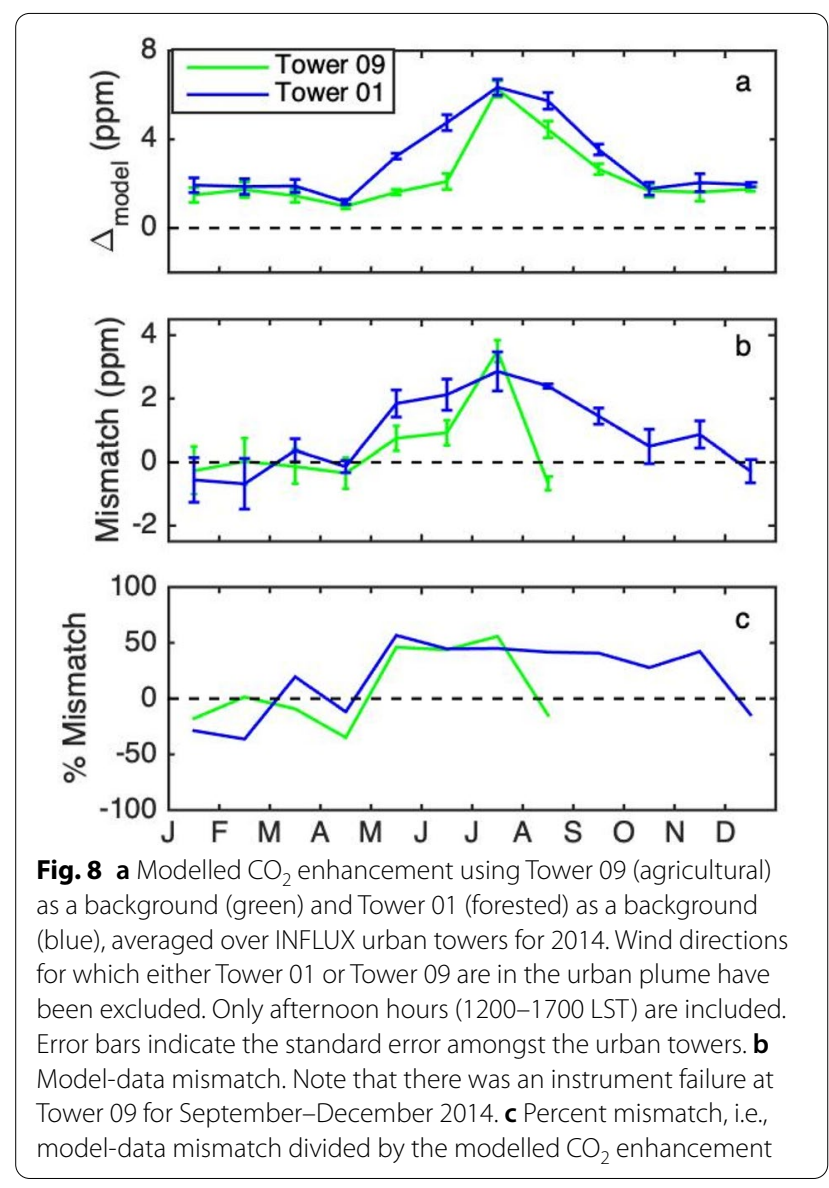


$1.7 \mathrm{ppm}$, whereas the observations showed the agricultural tower $\mathrm{CO}_{2}$ to be lower by $2.0 \mathrm{ppm}$.)

The INFLUX urban tower-averaged (Towers 02, 03, 06, 07 , and 10) model-data mismatch, resulting from a combination of differences attributable to fossil fuel fluxes, biogenic fluxes and transport, was larger during the growing season (May-September) compared to the dormant season (Fig. 8b). For the dormant season, the mean model-data mismatch was $-0.1 \pm 0.5 \mathrm{ppm}$. The mean growing season model-data mismatch was $1.1 \pm 1.7 \mathrm{ppm}$ for enhancements compared to Tower 09 (agricultural) and $2.1 \pm 0.5 \mathrm{ppm}$ for those compared to Tower 01 (forested), with the standard deviations calculated over the months. The modelled enhancements were positive in the growing season, likely indicating stronger modeled drawdown at the background sites than was observed, with the mismatch being higher for the forested background site. The INFLUX tower-averaged model-data mismatch averaged $25 \%$ of the modelled $\mathrm{CO}_{2}$ enhancement for Tower 09 and $29 \%$ for Tower 01 during the growing season.

\section{Agricultural tower $\mathrm{CO}_{2}$ background differences}

The median daytime $\mathrm{CO}_{2}$ at Towers 14 and 09 differed by up to $2.5 \mathrm{ppm}$ in the peak growing season, despite both being agricultural sites (Fig. 9). Tower 14, in westcentral Indiana is on the eastern edge of the highly productive U.S. corn belt (Additional file 1: Fig. S5). Tower 14 is located in Montgomery County, which produced $1.35 \times 10^{6} \mathrm{~kg}$ corn/harvested $\mathrm{km}^{2}$, whereas Hancock County (Tower 09) produced $1.06 \times 10^{6} \mathrm{~kg}$ corn/harvested $\mathrm{km}^{2}$ [48]. In addition, the area surrounding Tower 14 contains $37.1 \%$ corn landcover (" $\mathrm{CO}_{2}$ enhancements above background" section), whereas the area surrounding Tower 09 is $33.8 \%$ corn. Thus the combination of a higher percentage of corn coverage and more productive harvests is likely to have contributed to the additional

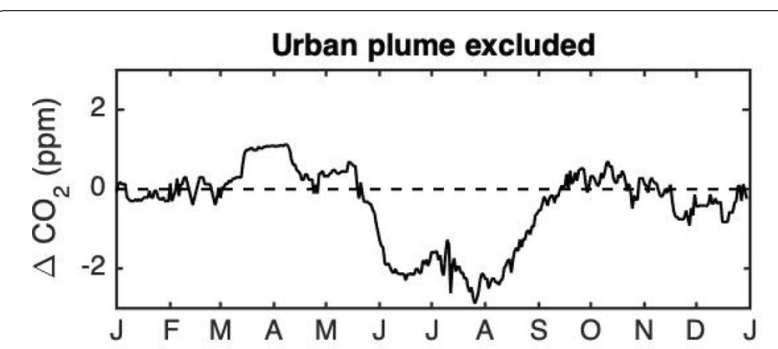

Fig. 9 Composited 31-day running median $\mathrm{CO}_{2}$ differences between Towers 09 and 14, both agricultural background towers. As for the previous results, data for which Tower 01 or Tower 09 was influenced by the urban plume were excluded from the analysis (WSW and NE). Tower 14 was not significantly affected by the urban plume
$\mathrm{CO}_{2}$ drawdown observed at Tower 14 compared to Tower 09.

We explored other potential causes, but none seem likely to explain the large observed differences between these two towers. Measurement height does likely contribute, but not enough to explain the difference (see also Section S4). The measurement heights of the three potential background towers (Towers 01, 09, and 14) are 121, 130, and $76 \mathrm{~m}$ AGL, respectively. Linearly interpolating the mean $\mathrm{CO}_{2}$ difference found between tower heights in the growing season at Tower 01 (Fig. S6), the magnitude of the difference between $76 \mathrm{~m}$ AGL and $121 \mathrm{~m}$ AGL was $0.3 \mathrm{ppm}$. This analysis is an overly conservative estimate since vertical $\mathrm{CO}_{2}$ gradients are non-linear [58]. Typical corn fluxes in July and August are about double those of forest (Fig. 2a), so the height effect difference between Tower 14 and Tower 09 is estimated to be no more than $0.6 \mathrm{ppm}$.

Although we ignored wind directions for which the primary plume from Indianapolis affected the background towers, there are still small urban areas within the footprints of the towers. The urban fraction within the $10-\mathrm{km}^{2}$ area contributing about $80 \%$ of the influence on the $\mathrm{CO}_{2}$ measurements at Tower 09 was $12.3 \%$, compared to $6.2 \%$ surrounding Tower 14 . Thus increased anthropogenic signal at Tower 09 may have somewhat reduced the apparent biological signal, increasing the difference between Tower 14 and Tower 09 . Tower 14 is outside the modeling domain, and thus has not been considered extensively in this work.

\section{Discussion/conclusions}

We examined $\mathrm{CO}_{2}$ enhancements as a function of time throughout the year using composites of over six years of data from towers in and around the city of Indianapolis, IN. Three possible background towers were considered, Tower 01 in a forested area southwest of the city, Tower 09 in an agricultural region east of the city, and Tower 14 in an agricultural region northwest of the city. The enhancement differed significantly depending on choice of background and time of year, being $2.8 \mathrm{ppm}$ higher in June and $1.8 \mathrm{ppm}$ lower in August using Tower 01 as a background compared to Tower 09 .

The most striking feature in the $\mathrm{CO}_{2}$ enhancements compared to agricultural Tower 09 as a background was an apparent maximum in August, with 31-day median enhancement at the urban towers up to $4.3-6.5 \mathrm{ppm}$, 2.6 times as large as those in the dormant season. This feature could be misinterpreted solely as an anthropogenic signal, but the cause was a combination of the effect of the biological signal upwind of the background tower, and a secondary maximum in the fossil fuel flux (Fig. 2b). Clearly the biological fluxes (and land cover 
types) upwind of the background measurement sites must be known in order to interpret $\mathrm{CO}_{2}$ enhancements throughout the year. Anthropogenic fluxes resulting from an inverse estimation which did not consider biological fluxes in the rural areas around the city would overestimate the summertime anthropogenic fluxes. We note that using a model-data hybrid approach for determination of background [16] minimizes the effect of the biogenic signal in the calculated enhancements. Our approach, using a measured background, means that the enhancements are quite dependent on the biogenic signal of the background towers, and the enhancements are not "anthropogenic" enhancements. In the next step, optimization of fluxes using an inversion [52], the biogenic portion is determined via either method of background determination. While we have focused on the biogenic signal at the background towers, urban biogenic $\mathrm{CO}_{2}$ fluxes also change with season [59]. $\mathrm{CO}_{2}$ drawdown by the urban biosphere affects the $\mathrm{CO}_{2}$ enhancements at urban towers compared to background towers, and is important to understand.

The difference in timing of fluxes from the different land cover types of the background towers appears to explain the shift in summertime peak for the urban towers from August when using agricultural Tower 09 as a background to July when using forested Tower 01 as a background.

While the differences in the growing season enhancements using different backgrounds were sizeable, a prediction of the difference between Tower 09 and Tower 01 $\mathrm{CO}_{2}$ based on differences in land cover type in the surrounding areas and the typical fluxes of these land cover types yielded a plausible explanation, with the difference attributable to the forest green-up preceding that of agriculture, but the agricultural peak drawdown being more intense. Forward modelled total $\mathrm{CO}_{2}$ using Hestia fossil fuel emissions and VPRM biogenic fluxes show that the biogenic model was able to represent the enhancements fairly well, with model-data mismatch of $1.1 \pm 1.7 \mathrm{ppm}$ for the agricultural background and $2.1 \pm 0.5 \mathrm{ppm}$ for the forested background during the growing season (25-29\% of the modelled $\mathrm{CO}_{2}$ enhancement) and $-0.1 \pm 0.5 \mathrm{ppm}$ during the dormant season. Developing and testing robust $\mathrm{CO}_{2}$ flux estimates for the rural ecosystems upwind of cities is therefore critical to year-round urban anthropogenic $\mathrm{CO}_{2}$ flux estimates. Further tuning of the biogenic model response, or a more advanced vegetation model in order to more fully capture the timing and productivity differences between the forested and agricultural sites considered here would likely improve the inversion results. The sensitivity of the inverse fluxes to the biogenic fluxes is of course dependent upon the fossil fuel emissions for the study area.
The growing season forward model to data mismatch was larger than the dormant season mismatch, suggesting that biogenic fluxes were a larger source of mismatch than the fossil fuel fluxes. The inversion of these data, separately optimizing fossil fuel and biogenic $\mathrm{CO}_{2}$ emissions, [52] indicated very little adjustment to the fossil fuel $\mathrm{CO}_{2}$ emissions from Hestia. While the larger uncertainty assigned to the prior biogenic flux may have played a role, this result further indicates that the biogenic model is a larger contributor to the model-data mismatch. Unfortunately, we were not able to use the flask measurements to decompose into biogenic and fossil fuel components of the mismatch because (1) the flasks were sampled when the winds were from the west/southwest, i.e., to a large extent, the wind directions ignored for this analysis, and (2) differing subset of towers for this analysis vs the flask availability. In the future, a flask sampling strategy including wind directions for which neither background tower is in the urban plume would provide further evidence.

The summertime increase in enhancement was larger in forward model results than is observed, indicating that the VPRM fluxes were in general too strong, or that the modelled biosphere was too weak within the urban domain. Further analysis will assess the performance of VPRM via flux towers and tune the biogenic model to improve accuracy. Accurate modelling of ecosystems will be crucial for accurate fluxes during the growing season, for both the approach presented here, based on a simple background tower or wind-direction dependent tower, and the model-data hybrid approach for background determination [16]. Another approach is to optimize the biogenic fluxes separately in the inversion [52].

Enhanced intensity of drawdown due to corn during the peak growing season months of July and August northwest of Indianapolis was the likely cause of the large difference in $\mathrm{CO}_{2}$ measured at Towers 09 and 14, both in agricultural areas. The discrepancy between background agricultural sites during the peak growing season months was similar in magnitude to the differences between urban towers and Tower 01 . Tower 14 is on the predominately downwind edge of the U.S. corn belt, and while there is corn grown in the area surrounding Tower 09 it is a less productive area overall. Persistent differences in $\mathrm{CO}_{2}$ between two background sites with similar land cover presents an additional challenge for vegetation models. The biogenic model may need to be further tuned to capture the differences between these agricultural sites with differing productivity. INFLUX is unique being on the edge of the U.S. corn belt, but in general, potential gradients in production and differing landcover type within domains for each study should be considered. Additional measurements, including flux tower eddy 
covariances are planned to learn more about the differences in $\mathrm{CO}_{2}$ drawdown between these locations.

Although the number of towers and timespan of the dataset is unprecedented for a study of $\mathrm{CO}_{2}$ mole fractions in and around a city, there were some limitations of this study. We used afternoon-averaged wind direction at the airport to exclude the afternoons for which the background towers were affected by the urban plume. Given the likelihood of wind direction changes throughout the day, back trajectory analysis would have been a more accurate way to exclude the urban plume, but is beyond the scope of this study. Additionally, although we estimated the effects of variable tower heights on our results and found them to be negligible (Additional file 1: Fig. S7), ideally all measurements would be made at the same height. In practice, this was not possible. Furthermore, we used a 10-km radius to categorize land cover types for each tower for the simple calculation shown in Fig. 5c. In reality, the area affecting the $\mathrm{CO}_{2}$ measured at each tower is much more complex and we did not address the seasonal cycle of the urban biosphere for the simple calculation. We have addressed these issues to a degree by comparing the observed enhancements to the forward modelled $\mathrm{CO}_{2}$. The modelled footprints were calculated on the inner, $1-\mathrm{km}$ resolution, $87 \mathrm{~km} \times 87 \mathrm{~km}$ domain, and likely extended beyond this domain. Future analysis will include footprints calculated on a larger domain.

Here we focus on the afternoon hours as these data are typically used in inversions. Afternoon is typically more well-mixed, allowing for less complicated interpretation and high fidelity modeling results. There is, however, critical information available during other times of day. Future analyses of nighttime respiration and the use of non-afternoon greenhouse gas data in inversions are likely to prove beneficial to understanding of the carbon cycle and reducing uncertainties.

This study in general highlights the importance of background choice in urban greenhouse gas studies. The magnitude of potential background differences depends on time of year and land cover types in the region. Indianapolis is a large city, but not a mega city, and determination of fluxes for larger cities with larger $\mathrm{CO}_{2}$ fluxes may be less affected by land cover-based differences in background towers. Still, careful consideration of land cover types is necessary in order to interpret $\mathrm{CO}_{2}$ tower network data throughout the growing season. Each city, depending on topography, climate, population, surrounding land cover and other factors, has unique challenges for the estimation of greenhouse gas emissions.

\section{Supplementary information}

The online version contains supplementary material available at https://doi. org/10.1186/s13021-020-00166-z.
Additional file 1: Figure $\mathrm{S} 1$. Afternoon average $\mathrm{CO}_{2}$ time series for the background towers. Figure $\mathbf{S}$. Hourly-averaged $\mathrm{CO}_{2}$ for the six specific days with the largest deviations amongst the potential background towers. Figure S3. Afternoon-average $\mathrm{CO} 2$ differences of background towers as a function of wind direction and season. Figure S4. Composited 31-day running median afternoon-average $\mathrm{CO}_{2}$ enhancements using alternate backgrounds. Figure S5. Corn production by county for 2017. Figure S6. Composited afternoon $\mathrm{CO}_{2}$ vertical profiles for growing and dormant seasons. Figure S7. Composited median afternoon-average $\mathrm{CO}_{2}$ enhancement from Tower 01, as a function of urban land cover fraction and tower height.

\section{Acknowledgements}

The authors thank B. Haupt (The Pennsylvania State University) for assistance with scripting for data ingest and pre-processing and S. Miller (The Pennsylvania State University) for help with data quality assurance. Earth Networks supported the maintenance of INFLUX in situ tower sites.

\section{Authors' contributions}

Contributed to conception and design: NLM, TL, KJD, SJR, KRG, JCT. Contributed to acquisition of in situ data: SJR, NLM, DKM. Contributed to modeling results: TL, AJD, JW, KRG, JL, GR. Contributed to analysis and interpretation of data: NLM, KJD, TL, JCT, NVB, SJR. Drafted article: NLM. All authors read and approved the final manuscript.

\section{Funding}

This work is supported by the National Institute of Standards and Technology (Project \# 70NANB10H245) and the National Oceanic and Atmospheric Administration (Award \# NA13OAR4310076). T. Lauvaux was also supported by the French research program Make Our Planet Great Again (project CIUDAD).

\section{Availability of data}

Miles NL, Richardson SJ, Davis KJ, Haupt BJ. In-situ tower atmospheric measurements of carbon dioxide, methane and carbon monoxide mole fraction for the Indianapolis Flux (INFLUX) project, Indianapolis, IN, USA. Data set available on-line from The Pennsylvania State University Data Commons, 2017b; http:// dx.doi.org/10.18113/D37G6P. For further information, see http://sites.psu.edu/ INFLUX.

\section{Competing interests}

The authors declare no competing interests.

\section{Author details}

${ }^{1}$ Department of Meteorology and Atmospheric Science, The Pennsylvania State University, University Park, PA 16802, USA. ${ }^{2}$ Earth and Environmental Systems Institute, The Pennsylvania State University, University Park, PA 16802, USA. ${ }^{3}$ Present Address: Laboratoire des Sciences du Climat et de I'Environnement (LSCE), 91190 Saint-Aubin, France. ${ }^{4}$ Present Address: FLIR Systems, Inc, West Lafayette, IN 47906, USA. ${ }^{5}$ Present Address: Utopus Insights, Inc, Valhalla, NY 10595, USA. ${ }^{6}$ Present Address: NASA Goddard Space Flight Center/Universities Space Research Association, Greenbelt, MD 20771, USA. ${ }^{7}$ Northern Arizona University, Flagstaff, AZ 86011, USA. ${ }^{8}$ Present Address: Environmental Systems Research Institute, Redlands, CA 92373, USA. ${ }^{9}$ Boston University, Boston, MA 02215, USA. ${ }^{10}$ Present Address: University of California, Irvine, CA 92697, USA. ${ }^{11}$ GNS Science, Lower Hutt 5040, New Zealand. ${ }^{12}$ CIRES, University of Colorado at Boulder, Boulder, CO, USA.

Received: 25 August 2020 Accepted: 18 December 2020

Published online: 30 January 2021

\section{References}

1. C40 Cities Climate Action Group, 2020; https://www.c40.org/resea rches/global-aggregation-of-city-climate-commitments-methodology. Accessed 11 Nov 2020.

2. Davis KJ, Deng A, Lauvaux T, Miles NL, Richardson SJ, Sarmiento DP, et al. The Indianapolis Flux Experiment (INFLUX): a test-bed for anthropogenic greenhouse gas emission measurement and monitoring. Elem Sci Anth. 2017. https://doi.org/10.1525/elementa.188. 
3. Boon A, Broquet G, Clifford DJ, Chevallier F, Butterfield DM, Pison I, et al. Analysis of the potential of near-ground measurements of $\mathrm{CO}_{2}$ and $\mathrm{CH}_{4}$ in London, UK, for the monitoring of city-scale emissions using an atmospheric transport model. Atmos Chem Phys. 2016. https://doi. org/10.5194/acp-16-6735-2016.

4. McKain K, Wofsy SC, Nehrkorn T, Eluszkiewicz J, Ehleringer JR, Stephens B. Assessment of ground-based atmospheric observations for verification of greenhouse gas emissions from an urban region. Proc Nat Acad Sci. 2012. https://doi.org/10.1073/pnas.1116645109.

5. Miles NL, Richardson SJ, Lauvaux T, Davis KJ, Turnbull J, Karion A, et al. Quantification of urban atmospheric boundary layer greenhouse gas dry mole fraction enhancements: results from the Indianapolis Flux Experiment (INFLUX). Elem Sci Anth. 2017. https://doi.org/10.1525/ elementa.12.

6. Nickless A, Rayner PJ, Engelbrecht F, Brunke E-G, Erni B, Scholes RJ. Estimates of $\mathrm{CO}_{2}$ fluxes over the city of Cape Town, South Africa, through Bayesian inverse modelling. Atmos Chem Phys. 2018. https:// doi.org/10.5194/acp-18-4765-2018.

7. Staufer J, Broquet G, Bréon F-M, Puygrenier V, Chevallier F, Xueref-Rémy I, et al. The first 1-year-long estimate of the Paris region fossil fuel $\mathrm{CO}_{2}$ emissions based on atmospheric inversion. Atmos Chem Phys. 2016. https://doi.org/10.5194/acp-16-14703-2016.

8. Verhulst KR, Karion A, Kim J, Salameh PK, Keeling RF, Newman S, et al. Carbon dioxide and methane measurements from the Los Angeles Megacity Carbon Project—Part 1: calibration, urban enhancements, and uncertainty estimates. Atmos Chem Phys. 2017. https://doi. org/10.5194/acp-17-8313-2017.

9. Miles NL, Richardson SJ, Davis KJ, Lauvaux T, Andrews AE, West TO, et al. Large amplitude spatial and temporal gradients in atmospheric boundary layer $\mathrm{CO}_{2}$ mole fractions detected with a tower-based network in the U.S. Upper Midwest. J Geophys Res B. 2012. https://doi. org/10.1029/2011jg001781.

10. Pal S, Davis KJ, Lauvaux T, Choi Y, DiGangi JP, et al. Greenhouse gas changes across summer frontal boundaries in the Eastern United States. J Geophys Res Atmos. 2020;125(5):e2019JD030526.

11. Lauvaux T, Schuh A, Uliasz M, Richardson S, Miles N, Andrews A, et al. Constraining the $\mathrm{CO}_{2}$ budget of the corn belt: exploring uncertainties from the assumptions in a mesoscale inverse system. Atmos Chem Phys. 2012. https://doi.org/10.5194/acp-12-337-2012.

12. Peters W, Jacobson AR, Sweeney C, Andrews AE, Conway TJ, Masarie K, et al. An atmospheric perspective on North American carbon dioxide exchange: CarbonTracker. Proc Natl Acad Sci. 2007;104:18925-30. https ://doi.org/10.1073/pnas.0708986104.

13. Lauvaux T, Miles N, Richardson S, Deng AJ, Davis K, Stauffer D, et al. Urban emissions of $\mathrm{CO}_{2}$ from Davos, Switzerland: the first real-time monitoring system using an atmospheric inversion technique. J Appl Meteor Climatol. 2013. https://doi.org/10.1175/jamc-d-13-038.1.

14. Bréon FM, Broquet G, Puygrenier V, Chevallier F, Xueref-Remy I, Ramonet $\mathrm{M}$, et al. An attempt at estimating Paris area $\mathrm{CO}_{2}$ emissions from atmospheric concentration measurements. Atmos Chem Phys. 2015. https://doi.org/10.5194/acp-15-1707-2015.

15. Xueref-Remy I, Dieudonn E, Vuillemin C, Lopez M, Lac C, Schmidt $M$, et al. Diurnal, synoptic and seasonal variability of atmospheric $\mathrm{CO}_{2}$ in the Paris megacity area. Atmos Chem Phys. 2018. https://doi. org/10.5194/acp-18-3335-2018.

16. Sargent M, Barrera Y, Nehrkorn T, Hutyra LR, Gately CK, Jones T, et al. Anthropogenic and biogenic $\mathrm{CO}_{2}$ fluxes in the Boston urban area. Proc Natl Acad Sci U S A. 2018. https://doi.org/10.1073/pnas.1803715115.

17. Mueller K, Yadav V, Lopez-Coto I, Karion A, Gourdji S, Martin C, et al. Siting background towers to characterize incoming air for urban greenhouse gas estimation: a case study in the Washington, DC/Baltimore area. J Geophys Res Atmos. 2018. https://doi.org/10.1002/2017JD027364.

18. Whetstone JR. Advances in urban greenhouse gas flux quantification: The Indianapolis Flux Experiment (INFLUX). Elem Sci Anth. 2018. https://doi. org/10.1525/elementa.282.

19. Turnbull JC, Sweeney C, Karion A, Newberger T, Tans P, et al. Towards quantification and source sector identification of fossil fuel $\mathrm{CO}_{2}$ emissions from an urban area: Results from the INFLUX experiment. J Geophys Res. 2015. https://doi.org/10.1002/2014JD022555.

20. Lauvaux T, Miles N, Deng A, Richardson S, Cambaliza MO, Davis KJ, et al. High resolution atmospheric inversion of urban $\mathrm{CO}_{2}$ emissions during the dormant season of the Indianapolis Flux Experiment (INFLUX). J Geophys Res Atmos. 2016. https://doi.org/10.1002/2015jd024473.

21. Turnbull JC, Karion A, Davis KJ, Lauvaux T, Miles NL, Richardson SJ, et al. Synthesis of urban $\mathrm{CO}_{2}$ emission estimates from multiple methods from the Indianapolis Flux Project (INFLUX). Environ Sci Techn. 2019. https:// doi.org/10.1021/acs.est.8b05552.

22. Kornei K. One fifth of Los Angeles's $\mathrm{CO}_{2}$ rises from lawns and golf, Eos 2018; https://doi.org/10.1029/2018eo112149.

23. Wu K, Lauvaux T, Davis KJ, Deng A, Lopez Coto I, Gurney KR, Patarasuk R. Joint inverse estimation of fossil fuel and biogenic $\mathrm{CO}_{2}$ fluxes in an urban environment: an observing system simulation experiment to assess the impact of multiple uncertainties. Elem Sci Anth. 2018;6(1):17. https://doi. org/10.1525/elementa.138.

24. Gervois S, de Noblet-Ducoudré N, Viovy N, Ciais P, Brisson N, Seguin B, et al. Including croplands in a global biosphere model: methodology and evaluation at specific sites. Earth Int. 2004:8:16.

25. Lokupitiya E, Denning S, Paustian K, Baker I, Schaefer K, Verma S, Meyers T, Bernacchi CJ, Suyker A, Fischer M. Incorporation of crop phenology in Simple Biosphere Model (SiBcrop) to improve land-atmosphere carbon exchanges from croplands. Biogeosciences. 2009;6:969-86. https://doi. org/10.5194/bg-6-969-2009.

26. Corbin KD, Denning AS, Lokupitiya EY, Schuh AE, Miles NL, Davis KJ, Richardson S, Baker IT. Assessing the impact of crops on regional $\mathrm{CO}_{2}$ fluxes and atmospheric concentrations. Tellus B. 2010. https://doi.org/10.111 1/j.1600-0889.2010.00485.x.

27. Zeng N, Zhao F, Collatz GJ, Kalnay E, Salawitch RJ, West TO, Luis G. Agricultural Green Revolution as a driver of increasing atmospheric $\mathrm{CO}_{2}$ seasonal amplitude. Nature. 2014. https://doi.org/10.1038/nature13893.

28. Briber BM, Hutyra LR, Dunn AL, Raciti SM, Munger JW. Variations in atmospheric $\mathrm{CO}_{2}$ mixing ratios across a Boston, MA urban to rural gradient. Land. 2013. https://doi.org/10.3390/land2030304.

29. Heimburger AMF, Harvey RM, Shepson PB, Stirm BH, Gore C. Assessing the optimized precision of the aircraft mass balance method for measurement of urban greenhouse gas emission rates through averaging. Elem Sci Anth. 2017. https://doi.org/10.1525/elementa.134.

30. Balashov NV, Davis KJ, Miles NL, Lauvaux T, Richardson SJ, Barkley ZR, Bonin TA. Background heterogeneity and other uncertainties in estimating urban methane flux: results from the Indianapolis Flux (INFLUX) Experiment. Atmos Chem Phys. 2020;20:4545-59. https://doi. org/10.5194/acp-20-4545-2020

31. United States Census Bureau 2020. City and town population totals: 2010-2019 (dataset). https://www.census.gov/data/tables/time-series/ demo/popest/2010s-total-cities-and-towns.html Accessed 19 August 2020.

32. Desert Research Institute, 2019. https://wrcc.dri.edu/cgi-bin/wea_windr ose.pl?laKEYE. Accessed 15 Nov 2019.

33. Jin S, Yang L, Danielson P, Homer C, Fry J, et al. A comprehensive change detection method for updating the National Land Cover Database to circa. Remote Sens Environ. 2013;2013(132):159-75. https://doi. org/10.1016/j.rse.2013.01.012.

34. Multi-Resolution Land Characteristics Consortium 2020. National Land Cover Database 2016 CONUS Land Cover. https://www.mrlc.gov/viewer/. Accessed 19 August 2020.

35. Kim Y, Moorcroft PR, Aleinov I, Puma MJ, Kiang NY. Variability of phenology and fluxes of water and carbon with observed and simulated soil moisture in the Ent Terrestrial Biosphere Model. Geosci Model Dev. 2015. https://doi.org/10.5194/gmd-8-3837-2015.

36. Hollinger SE, Bernacchi CJ, Meyers TP. Carbon budget of mature no-till ecosystem in North Central Region of the United States. Agric For Meteor. 2005:130:59-69.

37. Miles NL, Richardson SJ, Davis KJ, Haupt BJ. In-situ tower atmospheric measurements of carbon dioxide, methane and carbon monoxide mole fraction for the Indianapolis Flux (INFLUX) project, Indianapolis, IN, USA. Data set available on-line from The Pennsylvania State University Data Commons, 2017; doi.org/https://doi.org/10.18113/d37g6p.

38. Gurney KR, Razlivanov I, Song Y, Zhou Y, Benes B, Abdul-Massih M. Quantification of fossil fuel $\mathrm{CO}_{2}$ emissions on the building/street scale for a large U.S. city. Environ Sci Technol. 2012. https://doi.org/10.1021/es3011282.

39. Blasing TJ, Broniak CT, Marland G. The annual cycle of fossil-fuel carbon dioxide emissions in the United States. Tellus. 2005;57B:107-15. 
40. Ueyama M, Ando T. Diurnal, weekly, seasonal and spatial variabilities in carbon dioxide flux in different urban landscapes in Sakai, Japan. Atmos Chem Phys. 2016. https://doi.org/10.5194/acp-16-14727-2016.

41. Turnbull J, Guenther D, Karion A, Sweeney C, Anderson E, Andrew A, et al. An integrated flask sample collection system for greenhouse gas measurements. Atmos Meas Tech. 2012. https://doi.org/10.5194/ amt-5-2321-2012.

42. Richardson SJ, Miles NL, Davis KJ, Lauvaux T, Turnbull JC, Karion A, et al. $\mathrm{CO}_{2}, \mathrm{CO}$, and $\mathrm{CH}_{4}$ surface in situ measurement network in support of the Indianapolis Flux (INFLUX) Experiment. Elem Sci Anth. 2017. https://doi. org/10.1525/elementa.140.

43. Uliasz M. Lagrangian particle modeling in mesoscale applications. in Environmental Modelling II. (Computational Mechanics Publications, Southampton, UK), 1994; No. 16282, pp. 71-102.

44. Deng A, Seaman NL, Hunter GK, Stauffer DR. Evaluation of interregional transport using the MM5/SCIPUFF system. J Appl Meteor. 2004;43:1864-86.

45. Deng A, Stauffer DR, Gaudet BJ, Dudhia J, Hacker J, Bruyere C, et al. Update on WRF-ARW end-to-end multi-scale FDDA system. 10th Annual WRF Users'Workshop, Boulder, CO. 2009. http://www2.mmm.ucar.edu/ wrf/users/workshops/WS2009/abstracts/1-09.pdf. Accessed 17 Sep 2018.

46. Stauffer DR, Seaman NL. Multiscale Four-Dimensional Data Assimilation. J Appl Meteor. 1994. https://doi.org/10.1175/1520-0450(1994)033\%3c041 6:mfdda\%3e2.0.co;2.

47. Han W, Yang Z, Di L, Mueller R. CropScape: a web service based application for exploring and disseminating US conterminous geospatial cropland data products for decision support. Comput Electron Agric. 2012;84:111-23.

48. United States Department of Agriculture, National Agricultural Statistics Service (USDA NASS 2019). https://nassgeodata.gmu.edu/CropScape/, Washington, DC. Accessed 30 May 2019.

49. Bakwin PS, Tans PP, Hurst DF, Zhao C. Measurements of carbon dioxide on very tall towers: results of the NOAA/CMDL program. Tellus. 1998;50B:401-15.

50. Skamarock WC, Klemp JB. A time-split nonhydrostatic atmospheric model for weather research and forecasting applications. J Comput Phys. 2008;227:3465-85.

51. Deng A, Lauvaux T, Davis KJ, Gaudet BJ, Miles N, Richardson S, et al. Toward reduced transport errors in a high resolution urban $\mathrm{CO}_{2}$ inversion system. Elem Sci Anthropocene. 2017. https://doi.org/10.1525/eleme nta.133.

52. Lauvaux T, Gurney KR, Miles NL, Davis KJ, Richardson SJ, Deng A, Nathan BJ, Oda T, Wang JA, Hutyra LR, Turnbull JC. Policy-relevant assessment of urban greenhouse gas emissions. Environ Sci Tech. 2020. https://doi. org/10.1021/acs.est.0c00343.

53. Gurney KR, Liang J, Patarasuk R, O'Keeffe D, Hutchins M, Lauvaux T, Turnbull JC, Shepson PB. Reconciling the differences between a bottom-up and inverse-estimated FF $\mathrm{CO}_{2}$ emissions estimate in a large US urban area. Elem Sci Anth. 2017;5:44. https://doi.org/10.1525/elementa.137.

54. Gurney KR, Liang J, Keeffe D, Patarasuk R, Hutchins M, Huang J, et al. Comparison of global downscaled versus bottom-up fossil fuel $\mathrm{CO}_{2}$ emissions at the urban scale in four US urban areas. J Geophys Res Atmos. 2019;124:2823-40.

55. Hardiman BS, Wang JA, Hutyra LR, Gately CK, Getson JM, Friedl MA. Accounting for urban biogenic fluxes in regional carbon budgets. Sci Total Environ. 2017. https://doi.org/10.1016/j.scitotenv.2017.03.028.

56. Mahadevan P, Wofsy SC, Matross DM, Xiao X, Dunn AL, Lin JC, et al. A satellite-based biosphere parameterization for net ecosystem $\mathrm{CO}_{2}$ exchange: vegetation Photosynthesis and Respiration Model (VPRM). Global Biogeochem Cycles. 2008. https://doi.org/10.1029/2006gb002735.

57. Hilton TW, Davis KJ, Keller K. Evaluating terrestrial $\mathrm{CO}_{2}$ flux diagnoses and uncertainties from a simple land surface model and its residuals. Biogeosciences. 2014;11:217-35.

58. Wang W, Davis KJ, Yi C, Patton EG, Butler MP, Ricciuto DM, Bakwin PS. A note on top-down and bottom-up gradient functions over a forested site. Bound Layer Meteor. 2007. https://doi.org/10.1007/s1054 6-007-9162-0.

59. Miller JB, Lehman SJ, Verhulst KR, Miller CE, Duren RM, Yadav V, Newman $\mathrm{S}$, Sloop CD. Large and seasonally varying biospheric $\mathrm{CO}_{2}$ fluxes in the Los Angeles megacity revealed by atmospheric radiocarbon. Proc Natl Acad Sci USA. 2020;117(43):26681-7. https://doi.org/10.1073/pnas.2005253117

\section{Publisher's Note}

Springer Nature remains neutral with regard to jurisdictional claims in published maps and institutional affiliations.
Ready to submit your research? Choose BMC and benefit from:

- fast, convenient online submission

- thorough peer review by experienced researchers in your field

- rapid publication on acceptance

- support for research data, including large and complex data types

- gold Open Access which fosters wider collaboration and increased citations

- maximum visibility for your research: over $100 \mathrm{M}$ website views per year

At $\mathrm{BMC}$, research is always in progress.

Learn more biomedcentral.com/submissions 